\title{
WHO analgesic ladder gone astray: wider implications
}

\author{
Michael H Basler consultant in pain management, Paul W Keeley consultant palliative physician \\ Glasgow Royal Infirmary, Glasgow G4 0SF, UK
}

In the past the medical use of opioids has depended on many factors. ${ }^{1}$ Opioids are essential drugs that need to be safeguarded by appropriate use. ${ }^{2}$ Ballantyne and colleagues ${ }^{3}$ point out that the WHO analgesic ladder was developed for the treatment of terminal cancer and that the wider interpretation of this treatment pathway has led to problems. Many guidelines rely on the WHO ladder approach for the blanket treatment of cancer pain. ${ }^{4}$ Advances in treatment and increasing cancer survival have led to a rise in chronic complications that can cause serious pain. ${ }^{5}$ In our experience, the widespread use of the WHO ladder for cancer pain has led to serious opioid based problems in a small group of patients. Moreover, palliative care doctors have extended their role in the management of multiple chronic conditions that can be associated with pain. ${ }^{6}$ Opioids are the cornerstone of their therapeutic armamentarium. Lessons learnt by both pain clinicians and GPs about the WHO ladder need to be disseminated more widely. This should include oncologists and palliative care doctors as well as the wider medical fraternity. The medical duty of all doctors is to prevent hurt and stop harm, especially when the harm is iatrogenic.

Competing interests: No competing interests

Meldrum M. The ladder and the clock: cancer pain and public policy at the end of the twentieth century. J Pain Symptom Manage 2005;29:41-54. doi:10.1016/j.jpainsymman 2004.08.004. 15652438.

2 World Health Organization. WHO model list of essential medicines. 16th list (updated). 2010. http://www.who.int/medicines/publications/essentialmedicines/Updated_sixteenth adult_list_en.pdf.

3 Ballantyne JC, Kalso E, Stannard C. WHO analgesic ladder: a good concept gone astray. BMJ 2016;352:i20.26739664.

4 Portenoy RK. Treatment of cancer pain. Lancet 2011;377:2236-47. doi:10.1016/S01406736(11)60236-5. 21704873.

5 Burton AW, Fanciullo GJ, Beasley RD, Fisch MJ. Chronic pain in the cancer survivor: a new frontier. Pain Med 2007;8:189-98. doi:10.1111/j.1526-4637.2006.00220.x. 17305690.

6 Traue DC, Ross JR. Palliative care in non-malignant diseases. J R Soc Med 2005;98:503-6. doi:10.1258/jrsm.98.11.503. 16260799.

Published by the BMJ Publishing Group Limited. For permission to use (where not already granted under a licence) please go to http://group.bmj.com/group/rights-licensing/ permissions 